\title{
Narrative Economics and Behavioral Economics: contributions to the behavioral insights on post-Keynesian theory
}

\author{
Economia da Narrativa e Economia Comportamental: \\ contribuições para os insights comportamentais \\ na teoria pós-keynesiana
}

GABRIEL VILELA RESENDE FREITAS*

\begin{abstract}
RESUMO: O objetivo desta resenha é discutir a formação do conhecimento proposto por Keynes em seu Tratado sobre Probabilidade e o comportamento dos agentes econômicos em um cenário de incerteza apresentado em sua Teoria Geral, pelas perspectivas da Economia da Narrativa e Economia Comportamental. A hipótese a ser analisada é que, em um cenário de incerteza keynesiano, os agentes econômicos tendem a agir de acordo com seu contexto (social, geográfico, histórico, cultural), divulgando narrativas pelas quais se identificam, e orientam decisões que causam movimentos sensíveis nos agregados econômicos. Revisitando a literatura, podemos concluir que, reunindo a economia comportamental e a teoria da economia narrativa, a partir dos insights de Keynes sobre seus escritos, podemos perceber fortes evidências empíricas que podem ser analiticamente importantes na avaliação das flutuações econômicas.

PALAVRAS-CHAVE: Keynes; Economia da Narrativa; Economia Comportamental.
\end{abstract}

ABSTRACT: The objective of this review is to discuss the formation of knowledge proposed by Keynes on his Treatise on Probability, and the economic agents' behavior in an uncertainty scenario presented on his General Theory, by the Narrative Economics' and Behavioral Economics perspectives. The hypothesis that will be analyzed is that in a keynesian uncertainty scenario, economic agents tend to act according to their context (social, geographic, historic, cultural) spreading narratives by which they identify themselves and orient decisions that cause sensible movements on the economic aggregates. Revisiting the literature, we could conclude that by bringing together the behavioral economy and the narrative economy theory, we could, from the Keynes' insights on his writings, perceive strong empirical evidence that can be analytically important on the assessment of the economic fluctuations.

KEYWORDS: Keynes; Narrative Economics; Behavioral Economics.

JEL Classification: B50.

\footnotetext{
* Universidade Federal de Uberlândia, Uberlância/MG, Brasil. E-mail: gabrielvrf@hotmail.com. Orcid: https://orcid.org/0000-0002-7854-1574. Submitted: 1/June2020; Approved: 10/July/2020.
} 


\section{INTRODUCTION}

The objective of this paper is to discuss the formation of knowledge proposed by Keynes in his Treatise on Probability, and the behavior of agents within an uncertainty scenario presented in his General Theory, on the light of the "Narrative Economics" 1 and behavioral economy. In other words, how narratives (spread of popular stories, particularly those that concern to the human emotion interest) affect the building of expectation that condition the actions of agents. Moreover, we intend to discuss the importance of these narratives, once the construction of rational beliefs by reasoning, is done via acquiring knowledge from different sources (being them direct or indirect).

From the literature and examples assessed, we could notice that, on Keynes' Treatise on Probability, there are important insights on the build and spread of knowledge via argument, in a way that the formation of a rational belief not always leads to correct results, even when it is based on a set of premises that allows the logic bridge to the conclusion. We add to that, based on the "Narrative Economics" framework, that individual experiences can be built according to beliefs in stories that are sufficiently plausible (from the perspective of that individual, or group of individuals), even when they're not concrete or based on hard facts.

From the building of narratives and knowledge, we started the questioning that originated this paper: how narratives are related to the changes in expectation, adding or altering information whose result in the formation of new conclusions? Thus, our hypothesis is that, within keynesian uncertainty, the economic agents tend to act in accordance with their context (social, geographic, cultural and historic), reproducing the narratives with which they identify themselves, driving decisions that, at the end of the day, cause important movements in economic aggregates.

Our paper is divided in five sections in addition to this introduction. At the first part, we resume the discussion on the uncertainty realm done by Keynes in his General Theory and approximate this concept with the notions of rational belief in his Treatise on Probability. At the second part, we connect Keynes' theory with the theoretical framework of the behavioral economy. At the third section, we explore some important empirical evidence brought by the behavioral economy so we can, in the fourth section, discuss the building and spread of knowledge through narratives based on individual behavior and decision making. Finally, at the fifth section we briefly resume the topics on our final considerations.

\section{KEYNESIAN UNCERTAINTY AND AGENTS' BEHAVIOR}

Uncertainty about the occurrence of some determined event is something with which the agents must deal on the decision-making moment. The unfamiliarity with

\footnotetext{
${ }^{1}$ Shiller (2017).
} 
the exact results on any decision-making process is what forges the need of creating logic methods, that allows the human mind to formulate a bridge that links what is known and the expected goal. Evidently, the "bridge", or the logic, upon which one conclude something from one or more premises is subject to change, once not all the information is available (or can be considered simultaneously) at every moment.

By accepting that many arguments, despite being rational, are inconclusive, Keynes (1921) proposes that on the course of history of thoughts driven by logic, a perception that doubtful arguments are not logical was created and, thus, are not within its scope of study. If logic investigates the general principles of a valid thought, it is rational to considerate arguments upon which can be deposited some weight as much as those that can be effectively demonstrated.

Thus, one could think that probability is subjective, however, in what concerns logic, it is not. A proposition is not probable because of the will of the agents. When the facts are presented, what is probable or not in this circumstance does not depend on beliefs, it is given. The theory of probability is rational, therefore, because it considers the degrees of rational belief that can be allocated in determined situations, without being directly tied to the individual thoughts or beliefs, which in turn can be irrational.

According to Keynes (1921), from a proposition based on a determined corpus of knowledge, the changes in premises or opinions, show a new set of probabilities to the conclusions related to the new premises. That means that the probability of a conclusion based on a set of premises is more or less probable given the circumstances of the knowledge, i.e., the probability of a conclusion is dynamic, it can be changed.

Given the probabilistic reasoning and the formation of rational beliefs, one can realize that Keynes analyses uncertainty as if he were one of the subjects investigated (Ferrari Filho and Terra, 2016). This is an important factor, given that Keynes puts himself inside the uncertainty environment together with the subjects he studies. As said before, the building of knowledge is the goal of the connection between logic and the sets of propositions, however, as the agents don't have full knowledge about all of the future events, their conclusions and perceptions can be altered once new information appears. What we want to capture here is the caution so that the theory does not drift away from the reality, so it can still be useful and coherent with the real world. It is exactly this contact with the real world that is maintained on the analysis of the investment decision on Keynes (1936).

We try to understand now which types of interlinkages must be created to understand behavior and long-term expectations on the world of keynesian uncertainty. According to Keynes (1936), it would be unwise to assign importance to uncertain topics when one is building expectations, thus, one must navigate towards facts that deserve trust, even if their relevance is not as big as the other less known factors. Moreover, the facts upon which the agents know more about are located in the present, however, one the methods to build long-term expectations is to consider the current state of things and estimate it to the future, changing this estimation in the means that new information appears and demands alteration. 
Knowing that the decision-making environment is uncertain, the state of the expectations does not depend solely on the probability of the assumption, but also on the degree of confidence in said assumption. The state of confidence is responsible for the weighting that agents attribute to a determined assumption concerning the future. It is this state that defines, many times, that high uncertainty investments are made. Keynes (1936) highlights the human nature itself and the temptation to risk and adds that, as the probability bases to decision-making involving the future are largely scarce, if it weren't for this aspect of human nature, there would be far less risky investment based only on calculations.

Keynes (1936) observes that the foundation of the stock markets allows the revaluation of investments on a daily basis and this factor, at the same time that facilitates investment, also increases its instability, once the agents can move their capital (that was fixed outside the stock marked) accordingly to the new information. Keynes (1936) then proceeds to define, more clearly, the succession of the immediate future conditions that form the long-term:

For if there exist organized investment markets and if we can rely on the maintenance of the convention, an investor can legitimately encourage himself with the idea that the only risk he runs is that of a genuine change in the news over the near future, as to the likelihood of which he can attempt to form his own judgment, and which is unlikely to be very large. For, assuming that the convention holds good, it is only these changes which can affect the value of his investment, and he need not lose his sleep merely because he has not any notion what his investment will be worth ten years hence. Thus investment becomes reasonably 'safe' for the individual investor over short periods, and hence over a succession of short periods however many, if he can fairly rely on there being no breakdown in the convention and on his therefore having an opportunity to revise his judgment and change his investment, before there has been time for much to happen. Investments which are 'fixed' for the community are thus made 'liquid' for the individual. (p. 77).

The transformation of the long term into a succession of short periods is something that organized markets allowed and, not only this, the tools available to predict the near future are frequently more reliable (as they are closer to the present) than the tools used to predict the long-term future. Changings in expectations by acquiring new information allows capitals to flow to investments that appear to be safer on that given moment (or, in the worst-case scenario, will not collapse immediately).

Speculation, by itself, reinforces the instability flows instead of smoothing them, as the great speculators try to anticipate the average of the behavior to increase their capital during fluctuations. Adding to that, Keynes (1936) brings another important instability factor: that the human activities depends on spontaneous optimism rather than on a mathematical expectation, thus, by cooling down 
the enthusiasm and leaving only concrete mathematical expectations, enterprise faints. An important note that the author leaves is that the fear of losing is as devoid of logic as is the hope of winning.

We can then conclude that both economic depressions and prosperity are largely dependent on the confidence state of the businessperson, thus, to calculate the economic perspective must considerate both the nerves and hysteria. However, one cannot conclude that all economic fluctuations depend only on irrational psychological waves, in other words, the long-term expectation is somewhat stable. What we are trying to convey here is that one must not expect that the human decision involving the future (related to politics, economy and personal affairs) are strictly driven by mathematical calculation, once the bases themselves of these calculations are scarce. It is the innate human characteristics of risk taking that make the system endure. In a reality where the human brain tries to find the "alternatives as best it is able, calculating what it can, but often falling back to its motive on whim or sentiment or chance" (Keynes, 1936, p. 82).

\section{KEYNES AND THE BEHAVIORAL ECONOMY}

To understand how economic agents act when facing uncertainty, one must understand the way that on the average one acquires knowledge, estimate probabilities, make decisions and act on various scenarios. It is necessary to understand individual behavior as it presents itself on the real world. In that sense the theoretical framework of the behavioral economy is an important tool. This framework consists in identifying the ways that individual economic behavior differentiate itself from the mainstream ${ }^{2}$ and how this behavior is important to explain economic contexts (Mullainathan and Thaler, 2000).

The point in which behavioral economy is linked with Keynes' $(1936,3921)$ insights is the process of decision making under radical uncertainty. Given that the agents do not have enough reliable data to predict the future and make decisions, they start from assumptions, as highlighted by Koutsobinas (2015) and Dow (2008). Besides, Davidson (1991) arguments that in order to the rational expectations hypothesis to provide a theory about formation of expectations without persistent errors, it is necessary that the subjective expectations converge with the objective ones at any point in time, they also have to be functions originated from an ergodic stochastic process, in which both the estimated averages and the past observations are not persistently different from the averages in future observations.

According to Davidson (1991), individuals live in an environment that they often do not know what's going to happen in the future, so they avoid making decisions, or they follow their "animal spirits" and engage in a behavior of decision-making

\footnotetext{
${ }^{2}$ The mainstream model of economic behavior assumes that agents maximize their utility, are rational and their actions are self-interested.
} 
based on their gut feeling. This aspect is well described by Dequech (2003, p. 153), that defines the animal spirits as an "optimistic disposition to face uncertainty".

It is based on the uncertainty that Carvalho (2009) puts the "state of confidence" as one of Keynes' most important thesis. Trust in one's expectation depends on how much of it is explained by the assumptions (and not by the information) and the confidence that the agent weights on these assumptions. The same quantitative expectation can reflect a vast number of decisions, that are made in accordance with the individual experiences, as explained in Tversky and Kahneman (1974) and Kahneman and Frederick (2001).

One can argue that the decision making is not a rational exercise per se, but an entanglement of reason, emotion, trust and context. As explored by Dow (2008), psychology provides the unconscious motivation for the behavior, highlighting that Keynes also suggests heuristic processes that drive the building of expectations, one example being on the planning for the future, in which agents tend to use the present as benchmark.

In his 2010 paper, Paul Davidson observes that Keynes, on the first half of the twentieth century, had already have important insights that would make him an author that the behavioral economists should look upon, be by the adaptation of expectations when new information arises, be by the convention behavior, then called "herd behavior". Davidson (2010) highlights that the findings of contemporaneous neuroscience that provide strong empirical evidence to behavioral economists are also a huge support for the post-keynesian assumption that the axiom of ergodicity (ergodic stochastic processes) should be rejected in order to understand the decision making process within a monetary economy of production.

Despite disagreeing that Keynes was the "first behavioral economist", the conclusion of Davidson (2010), King (2013) agrees with the fact that behavioral economy has more to learn from the post-keynesian framework than the other way around. Still, we can see on both King (2013) and Jefferson and King (2010) papers that the references on behavioral economy in post-keynesian papers are scares (and vice-versa), even when both areas would have much to benefit should they unite their research agendas.

It is known that the progress on neuroscience allow behavioral explanations that differentiate themselves largely from the conclusions of the rational expectations' framework about the agent's economic behavior. Moreover, the neurological evidence allowed by the contemporaneous neurological tools provide solid evidence for the heuristic studies to base themselves on a psychological behavioral theory (Koutsobinas, 2015).

Finally, Davidson (2010) calls attention to neuroscientific evidence that the human brain "activates" different parts according to the context in which it has to make decisions, be in a context that the agent has knowledge about the future, or in a context that they do not have this information, i.e., within an uncertainty scenario. 


\section{CONTRIBUTIONS FROM THE BEHAVIORAL ECONOMY ON THE DECISION-MAKING}

The literature reviewed up to this point emerged, because neoclassicist's strict rationality was unable to provide answers to all the questions regarding economic behavior on an uncertain world, in other words, did not present the expected answers to solve real world problems about economic behavior. So, when the consequences of the choices were not previously known (or even vaguely known) to the agents, or if the economic agent did not have an utility function well defined and compatible with other agents, the strict rationality theory began to be questioned or, "relaxed" as new ways to analyze behavior appeared (Simon, 1968).

Starting from the cognitive limitations on human mind and incapacity to evaluate all the alternatives and results for each choice (two fundamental problems in decision making), Simon (1968) suggests the possibility that a different approach was necessary to tackle this analysis. By presenting an example on the building of a playground in Milwaukee, in which the administrators of public construction and recreation disagreed about the budget allocation, between maintenance of installations and supervision of recreation, the author questions why they did not simply look at the marginal returns on the allocation of expenditures on both activities and chose the one with the lowest marginal costs.

Simon (1968) argues that the activity in which the marginal returns were lower was not the one picked, because the administrators could not, intellectually, do it. Not only there was not a measurable production function upon which they could make statistic inferences, the qualitative knowledge about the playground was not compatible among the administrators. From this situation, the author observes that when one cannot link a decision to a certain objective function, the decisions are taken according to secondary objectives, in other words, its formulation will depend on the knowledge and experience of the management in each site.

The situation portrayed above underline the need to create a new methodology to analyze decision making; one that could turn unapproachable problems into plausible ones. Some of these procedures could be: search of satisfactory solutions ${ }^{3}$ instead of the ones that optimize a utility function; substitution of abstract objectives for tangible subobjectives, or, still, the division of the tasks among many specialists.

Barros (2010) calls attention to the discussion proposed by Simon (1957) that in his book Models of man, social and rational brought the concept of restrict rationality, i.e., the incapacity to exercise strict rationality of the neoclassic theory. The bridge between rationality and behavior is the concept of "decision", being the decision the process in which a choice is made. The criteria to make this choice is theoretically based on rationality, in other words, the agents are intentionally rational (Barros, 2010).

\footnotetext{
${ }^{3}$ Search for alternatives that are "good enough" according to pre-established criteria (Barros, 2010).
} 
On the field of finance, Shiller (2003) argues that the emerging of anomalies related to price volatility on the capital markets highlighted limitations about the explanatory capacities of the Efficient Markets Theory (EMT), i.e., the appearance of volatility on prices could not find a satisfactory explanation within the EMT framework. Evidence show that the volatility in capital market prices could occur with no concrete basis, they could be movements of mass psychology and herd behaviors.

According to Shiller (2003) the methodological incapacity of the EMT related to unexpected movements in aggregate markets' prices was one of the reasons that unsettled researchers when they started looking for research alternatives. To the scope of this paper, one of the most extensively used lines of research of the socalled Behavioral Finance is the models of feedback. The author states that the feedback theory appeared first in magazines and newspapers (or even public observations) rather than in academic papers. These models consist on the fact that, when asset prices rise, it attracts public attention, which in turn causes some enthusiasm. The process of spreading this enthusiasm causes that asset to be even more demanded, its price goes up again and this process remains while the feedback is positive and continuous. At some point, prices "go up because it is believed that they're going up" until this becomes, eventually, unsustainable.

Shiller (2003) points out that the casual observations on day-to-day conversation, whose result can be envy of someone else's financial success, or questioning of the growth in prices of some asset could be sufficient to overcome doubts based on rational principles about these subjects and, at any moment, begin to better explain the randomness of the prices than the objective statistical analysis. Resuming what's been said by Keynes, not a lot of decisions would be made based solely on statistical analysis, in other words, there is an additional "component" related to the social behavior that has a non-negligible weight on the matter.

Mullainathan and Thaler (2000) question the hypothesis of the mainstream economy and present empirical evidence that the actions of human beings: a) involve altruism; b) are not always maximizing its own well-being and c) are inconsistent from a rational point of view (in terms of its internal logic). Moreover, Tversky and Kahneman (1974) state that agents cannot assess correctly (both because of a lack of sufficient cognitive capacity and time) all the information at their disposal, which makes them incur in probabilistic errors even when they have enough information to not make such mistakes.

Mullainathan and Thaler (2000) also find evidence that can exist a complete lack of learning from mistakes, even with infinite horizons. The authors start from the simple assumption that, while that are costs of opportunity involving learning and experimentation with a new strategy, the "player" will remain stuck on a suboptimal equilibrium simply because the cost of trying something new is higher than the cost of continuing doing the same thing. Mullainathan and Thaler (2000) state that this conclusion reinforces the statement of Keynes that in the long-run we will all be dead, because the optimal equilibrium may never happen, or "take too long" to happen. 


\section{THE NARRATIVES AND THE BEHAVIOR OF AGENTS}

The behavioral economy framework brings an import insight about the agents' considerations on decision making. This framework not only underlines empirical evidence from Keynes' writings, it also expands on some concepts, like the probabilistic judgement on Tversky and Kahneman (1974), as we understand to be an important additive to the Treatise on Probabilities.

Evidently, the agents' economic behavior on the formation of knowledge also reflects the way in which this knowledge is spread by stories or narratives. Even the understanding of the world is bound to subjective behavior and the way that the brain works and interprets external stimuli. These interpretations cannot be decontextualized, i.e., the reality of each person deeply influences the way that she perceives the world around her.

According to Shiller (2017), narrative economics is the study of spreading and dynamics of popular narratives, of the stories, particularly those of emotional and human interest and how they change through time to understand economic fluctuations. Sometimes one must consider that the severity of a recession can be related to the degree of vividness and extent of the narratives around it, and not only the economic return or the multipliers from economic policy.

Is his study, Shiller (2017) uses the term "narrative" to refer to stories told by various people, be in the news, be on social media, that are capable of bringing emotions on others. There are evidences that the probabilistic judgement is largely affected by heuristics (Tversky and Kahneman, 1974) and thus, the narratives do not need to be necessarily feasible (from an objective point of view), they need to be representative of what the average of the population knows. Thereby, a narrative that is coherent to the average of the population's knowledge do not necessarily need to be truthful to be spread. In fact, important studies about the spread of false information on social media has been gaining ground recently, as one could see in Vosoughi et al. (2018) and Guess and Nyhan (2018).

We add to the discussion about the spreading of misinformation the discussion proposed by Akerlof and Kraton (2000) that there are a series of behaviors based on one's identity. By identity, we mean social belonging to a certain group, class, ethnicity, gender, etc. or, even, the way that the individual perceives his belonging in the world, his place compared to the others. In this paper, Akerlof and Kraton propose a utility function in which individuals get different payoffs according to certain behaviors within distinct social groups that allows for distinct identities. This utility function has an interesting characteristic, once agents will not necessarily choose payoffs to maximize it, i.e., one's identity is not always something upon which one has agency to control. As underlined by Akerlof and Kraton (2000), this function does not assume that agents are self-aware of their own motivations, as if they could choose the identity that serves better to maximize that function.

Moreover, social behavior and interaction among people suggest that behaviors that put individuals in distinct groups (distinct identities) affect the well-being of others, in other words, that is some behavioral externality among different groups 
that affect the identities of others. According to Akerlof and Kraton (2000), psychologic studies demonstrate that the sense of "self" of, the "ego" is a primary force to the behavior and, besides that, is intimately related to the social configuration. The identity is linked to social categories, and people identify or differentiate themselves according to these social categories.

The formation of identity is bound to the formation of groups, that are themselves nothing else than a random set of labels and attributions. The subjects are more susceptible to pay attention to those which the labels are similar to their own and to avoid those that differentiate, adding to that, the subjects attribute a bigger weight to the opinions of those that belong to their own group. Akerlof and Kraton (2000) argue that to develop personality, psychologists agree that the internalization of "behavioral rules" is a key aspect, and not only that, but the violation of these internal rules causes anxiety. The identity, "self", "ego" is the constant defense against the violation of their own internal rules, in other words, is to persistently try to avoid anxiety.

Groups are defense mechanisms against the noncompliance of each one's internal rules. In a group that fulfils a determined set of rules that is common among its participants, people find constant validation of their own beliefs and this brings comfort. Searching for acceptance allows that interpersonal relations base themselves on the sharing of feelings, thoughts, beliefs, that is the mind trying to understand the world according to its own perspective. In the same measure that the interior of the group brings comfort, its exterior serves as a threat to identity, once other groups' behavior may disturb one's internal equilibrium. That is why actions such as self-mutilation (as tattoos, piercings, steroids, etc.) can cause extreme discomfort and anxiety on the ones that disagree with said actions.

We understand identity as an important fuel to the building of narratives that appeal to the masses. Shiller (2017) argues that it is impossible to know, a priori, if a narrative will have this "viral" characteristic, as, by spreading a story, one does not know the appeal it will have or even the way that other groups will interpret it. In this context, identity particularities within the society will define which kinds of stories will be spread or, in other words, how this population attributes labels to different groups may define which kind of narrative will be "told".

The character of telling stories is an attribute of human minds, common to societies, that begins to be treated as a key part of thought and motivation. The importance of the feedback that stories have on social gatherings, be verbal or, more recently, via social media is an important evidence that human mind struggles to reach a permanent understanding of events and turns this understanding into narratives built-in social interactions. The transmission of these narratives to economic fluctuations can be found in this section of Shiller's (2017) paper:

\footnotetext{
${ }^{4}$ This is a comparative term with the reproduction of a virus, that spread rapidly, applied to the concept of spread of a determined story
} 
There is a daunting amount in the scholarly literature about narratives, in a number of academic departments, and associated concepts of memetics, norms, social epidemics, contagion of ideas. While we may never be able to explain why some narratives "go viral" and significantly influence thinking while other narratives do not, we would be wise do add some analysis of what people are talking about if we are do search for the source of economic fluctuations. We economists should not just throw up our hands and decide to ignore this vast literature. We need to understand the narrative basis for macroeconomic fluctuations, and to think about how narrative economics ought to be more informing of policy actions now and in the future

The emotional characteristic on decision making has been verified on several empirical papers, such as Zhang et al. (2011), that concludes that emotional effervescence on Twitter is negatively correlated to the growth rate of Dow Jones and positively correlated with the VIX index (volatility index based on S\&P stocks and options). Nguyen et al. (2015) proposed a method based on the analysis of sentiment on social media that could predict $60 \%$ of the stock's prices the day after.

Shiller (2009) discusses that high valuations of stocks in 2008 were not made necessarily with a careful study of long-term investment, they were substantially driven by emotions and common-sense perceptions. Not only that, but this behavior was also largely influenced by news and the media's interest to lure more readers and spectators, with little care about the technical analysis to give a better perspective to the population.

The problem of assessment within a market that leads to false impressions of investment is highlighted both by Dow (2008) and Shiller (2009). For these authors, agents fail to notice objective analysis and start behaving "boldly" when they are euphoric. In addition, when technical analysis separates itself from belief and optimism, the agents tend to ignore them when the environment is on the optimistic side.

Our discussion demonstrates that agent's behavior is influenced by several social, emotional and heuristic factors, in a world where representativeness and context matter to decision-making. This argument drives itself away from the strict rationality hypothesis and, according to the literature, it seems to approach from the real world in terms of predicting events and valuating the risks.

Radical uncertainty on a keynesian world is a phenomenon that must not be neglected and treated as exogenous, for it is intrinsically bound to decision-making on investment, spreading of information and creation of knowledge. At the end of the day, we argue that narrative economics has its bases on the behavioral economy framework, and both are linked with Keynes' thesis about decision-making within an uncertainty environment. 


\section{CONCLUDING REMARKS}

It is evident that Keynes had important insights in his writings from the beginning of the XX century, both from a behavioral point, to the formulation of knowledge and the agents' decision-making process. The behavioral economy framework associated with the narrative economics can be a fertile research agenda, once the capacity to perceive, document and measure typically human behavioral patterns in a society is growing fast on the last years. Analytical instruments based on artificial intelligence and intelligent analysis of data, together with the expansion of social media (and social data) is paving the way to several studies that try to predict behavior based on sentiments and/or stories. The results of behavioral considerations and measuring are showing to be positive and reliable on the prediction of movements in economic aggregates.

\section{REFERENCES}

AKERLOF, George A.; KRANTON, Rachel E. (2000) "Economics and identity". The Quarterly Journal of Economics, v. 115, n. 3, p. 715-753.

BARROS, Gustavo. Herbert A. (2010) "Simon and the concept of rationality: boundaries and procedures". Brazilian Journal of Political Economy, v. 30, n. 3, p. 455-472.

CARVALHO, Fernando Cardim de. (2009) “O retorno de Keynes”. Novos Estudos-CEBRAP, n. 83, p. 91-101.

DAVIDSON, Paul. (2010) "Behavioral economists should make a turn and learn from Keynes and Post-Keynesian economics”. Journal of Post-Keynesian Economics, v. 33, n. 2, p. 251-254.

DAVIDSON, Paul. (1991) "Is probability theory relevant for uncertainty? A Post-Keynesian perspective". Journal of Economic Perspectives, v. 5, n. 1, p. 129-143.

DEQUECH, D. (2003) “Conventional and Unconventional Behavior Under Uncertainty”. Journal of Post-Keynesian Economics. Fall, 26 (1), 145-168.

DOW, Sheila. (2010) The psychology of financial markets: Keynes, Minsky and emotional finance. University of Stirling.

GUESS, Andrew; NYHAN, Brendan; REIFLER, Jason.(2018) Selective Exposure to Misinformation: Evidence from the consumption of fake news during the 2016 US presidential campaign. 2018.

JEFFERSON, Therese; KING, J. E. (2010) "Can Post-Keynesians make better use of behavioral economics?”. Journal of Post-Keynesian Economics, v. 33, n. 2, p. 211-234.

KAHNEMAN, Daniel; FREDERICK, Shane. (2002) "Representativeness revisited: Attribute substitution in intuitive judgment". Heuristics and biases: The psychology of intuitive judgment, v. 49, p. 81.

KAHNEMAN, Daniel; KNETSCH, Jack L.; THALER, Richard H. (1986) "Fairness and the assumptions of economics." Journal of Business, p. S285-S300.

KAHNEMAN, Daniel; KNETSCH, Jack L.; THALER, Richard H. (2008) The endowment effect: Evidence of losses valued more than gains. Handbook of Experimental Economics Results, v. 1, p. 939-948.

KEYNES, John Maynard.(2013) A Treatise on Probability. Courier Corporation.

KEYNES, John Maynard. (2016) General theory of employment, interest and money. Atlantic Publishers \& Dist.

KING, John E. (2013) “Should post-Keynesians make a behavioural turn?”. European Journal of Economics and Economic Policies, v. 10 (2), pp. 231-242. 
KOUTSOBINAS, Thodoris T. (2014) "Keynes as the first behavioral economist: the case of the attribute-substitution heuristic." Journal of Post-Keynesian Economics, v. 37, n. 2, p. 337-355.

MULLAINATHAN, Sendhil; THALER, Richard H. (2000) "Behavioral economics". National Bureau of Economic Research, 2000.

NGUYEN, Thien Hai; SHIRAI, Kiyoaki; VELCIN, Julien. (2015) Sentiment analysis on social media for stock movement prediction. Expert Systems with Applications, v. 42, n. 24, p. 9603-9611.

RAINES, J. Patrick; LEATHERS, Charles G. (2011) "Behavioral finance and Post-Keynesian-institutionalist theories of financial markets". Journal of Post-Keynesian Economics, v. 33, n. 4, p. 539554.

SHILLER, Robert C. (2000) “Irrational exuberance”. Philosophy \& Public Policy Quarterly, v. 20, n. 1, p. 18-23.

SHILLER, Robert J. (2003) "From efficient markets theory to behavioral finance". Journal of economic perspectives, v. 17, n. 1, p. 83-104.

SHILLER, Robert J. (2017) “Narrative Economics”. American Economic Review, v. 107, n. 4, p. $967-$ 1004.

SIMON, H. A. (1968) "Rationality as process and as product of thought". American Economic Review, v. 68 , no. 2, pp. 1-16.

SIMON, Herbert A. (1957) Models of Man, Social and Rational: Mathematical Essays on Rational Human Behavior in a Social Setting. New York; John Wiley and Sons.

TERRA, Fábio Henrique Bittes; FERRARI FILHO, Fernando. (2016) "Reflexões sobre o método em Keynes". Revista de Economia Política, vol. 36, n. 1 (142), pp. 70-90.

TVERSKY, Amos; KAHNEMAN, Daniel. (1974) “Judgment under uncertainty: Heuristics and biases”. Science, v. 185, n. 4157, p. 1124-1131.

VOSOUGHI, Soroush; ROY, Deb; ARAL, Sinan. (2018) "The spread of true and false news online". Science, v. 359, n. 6380, p. 1146-1151.

ZHANG, Xue; FUEHRES, Hauke; GLOOR, Peter A. (2011) Predicting stock market indicators through twitter "I hope it is not as bad as I fear". Procedia-Social and Behavioral Sciences, v. 26, p. 55-62. 